\title{
SOME REMARKS ON THE DYNAMICS OF STRONG ACTOR / WEAK ACTOR INTERACTION
}

\author{
Zoltan JOBBAGY \\ University of Public Service, Budapest, Hungary \\ jobbagy.zoltan@uni-nke.hu \\ Goran BOROS \\ Croatian Military Academy “Dr. Franjo Tuđman”, Zagreb, Croatia \\ goran.boros@morh.hr \\ Levente Sandor KOVATS \\ University of Public Service, Budapest, Hungary \\ kovats.levente@uni-nke.hu
}

\begin{abstract}
The emergence of weak actors on global scale is one among the many undesired consequences of the post Cold War period. In a globalized world, weak actors increasingly possess the capability and will to challenge the existing status quo set earlier by strong actors. The complexity of the international theatre provides weak actors with an abundance of opportunities to become successful over a long period. From a military point of view strong actor / weak actor interaction becomes manifest when the latter prosecutes a special type of war. This war is asymmetric, irregular and of low intensity. It poses a significant challenge to the strong actor and can bog him down into confusing and ambiguous military actions. In these actions the strong actor often finds himself in messy situations he can mostly master by improvisation. To better understand the strong actor / weak actor interaction and the resulting special type of war the authors suggest to reject the classical theorizing of war and advocate a different sort of thinking instead.
\end{abstract}

KEYWORDS: actor, war, asymmetry, complexity, adaptation

\section{Introduction}

NATO tries to maintain a security posture that is favourable for the member states' values and interests. The last decades however, made clear that armed conflicts are interminable and feature an abundance of strong actor / weak actor interactions. These interactions affect the worldwide system as globalization offers a limitless terrain. Strong actor / weak actor interactions can erupt anytime and anywhere, and display a lethal violence including terror and counter-terror (Hardt \& Negri, 2004). The emergence of weak actors on global scale is one among the many undesired consequences of the post Cold War period. In a globalized world, weak actors increasingly possess the capability and will to challenge the existing status quo set by strong actors. Unlike in 
the traditional international constellation in which strong actors primarily interact with other strong actors, the last three decades witnessed strong actors increasingly interacting with various sort of weak actors. The complexity of the international theatre provides the latter actors with an abundance of opportunity to become successful even over a long period of time (Porkolab, 2013).

The strong actor / weak actor interaction very often results in a confrontation that features a special type of war. This war is often asymmetric, irregular and of low intensity. The consequences are serious as an examination of the outcome of asymmetric conflicts in the last two hundred years reveals: weak actors increasingly win asymmetric conflicts. The tendency is dangerous since the percental outcome of strong actor / weak actor interactions dropped from 88,2:11,8 in the period between $1800-1849$, to $79,5: 20,5$ in the period between $1850-1899$, to $55,1: 44,9$ in the period between 1900-1949, and to $45: 55$ in the period between 1950-1998 (ArregiunToft, 2001). The weak actor very often uses time to help its cause against the strong actor. Clausewitz stated that one can win by using time. Main goals include the setting of limited objectives, for example causing small but continuous casualties to enemies units. In this way, the weak actor can exhaust the strong actor over time (Clausewitz, 1993).

The article consists of four parts and aims at developing a coherent framework that departs from strong actor / weak actor interaction and the resulting special type of war. It then details certain problems posed by causal explanations, highlights the multitude of factors that must be taken into considerations when waging war, and emphasizes the need for a different conceptualization that takes advantage of biological evolution and adaptation. In terms of research methodology the article can be seen as a descriptive, reflective and explanatory study. It is descriptive as it describes strong actor / weak actor interaction and the resulting special type of war. It as reflective since by evaluating the underlying theories they use Clausewitz's epic volume of $\mathrm{On}$ War as reference, and it is explanatory since in case of inconsistencies are discovered, the authors identify and explain the contributory factors in detail.

\section{Special Type of War}

Strong actor / weak actor interaction is not a new phenomenon as it stands for campaigns of special scope and condition conducted against an adversary who would not meet in the open field. In these campaigns the strong actor very often struggles (Callwell, 1906). From a military point of view strong actor / weak actor interaction arises when one actor prosecutes the above mentioned special type of war. In some cases, such war may start after the defeat of the regular armed forces of the weak actor. It is normally waged by a loose network of combatants and poses a significant challenge to the strong actor. These combatants take mostly an indirect approach as they can occupy large areas; render the roads between cities and often the cities themselves unsafe (Schmitt, 1963; Creveld, 1991). Fighting networks that scarcely display hierarchical structures is difficult, occasionally impossible. They pose a significant challenge to the strong actor and can bog him down into confusing and ambiguous military actions. The strong actor often finds himself in messy situations he can master only by improvisation (Zinni, 2000).

This special type of war featuring asymmetry, irregularity and low intensity extends to and implies unconventional way of using means, methods and tactics by the weak actor to destabilize the environment and make the strong actor vulnerable. Actions of the weak actor deliberately include non-military civilian targets, not respecting the norms of the law of war, and the principles of restrictions in the use of 
weapons and force. The waging of this special type of war is very often described by the strong actor with the prefix counter: counter-irregular, counter-insurgency, or counter-terrorist (Heintschel von Heinegg, 2012). This requires the strong actor to plan, develop and apply specific response techniques over longer time periods with more or less (un)successful results in defeating the weak actor and ending the conflict.

The strong actor is often biased and is unable to see the resulting violence in a social context. He tends to ignore that cruelty and destructiveness of this special type of war express basic social conditions. The social context reflects social existence of a society with which this special type of war evolves (Coker, 2002). The enmity inherent in the strong actor / weak actor interaction can become real over time, including continuous terror and counterterror. This may lead to a vicious circle and result in cruelty, collective punishment, even in participation in genocide. The unavoidable circle of terror and counter-terror including various sorts of war crime leaves nothing else for the strong actor but to criminalize the weak by calling him a terrorist (Schmitt, 1963). Treating terrorists often requires premeditated actions also against the civil population. These actions include psychological operations, information operations, and civil-military relations, just to name a few. Due to the methods employed the strong actor very often becomes counter-insurgent or counter-terrorist, and he may even regard and call himself as such. One possible result of the strong actor / weak actor interaction is the shattering of existing social structures that comes as the result of insecurity, anxiety, and common mistrust (Schmitt, 1963).

The two major involvements of NATO in the first decade of the $21^{\text {st }}$ century waged in Iraq and Afghanistan were, despite the Alliance's clear technological and material advantage, long campaigns that did not end with a clear defeat of the weak actor. In a classic article published in the Foreign Affairs half a century ago Henry Kissinger lamented on what went wrong during the strong actor / weak actor interaction in Viet Nam. He concluded that the Americans wanted to fight a military war, but the adversary fought a political one. The Americans sought physical attrition, whereas the adversary preferred psychological exhaustion. During the war the Americans lost sight of one of the cardinal maxims of this special type of war: the weaker actor wins if he does not lose and the stronger actor loses if he does not win (Kissinger, 1969). Thus the weak actor tried to exhaust the strong actor and forced the strong actor to change his political objective. In modern conflicts, exhaustion is not only about causing high military casualties, but to remit the political support in the home country of the strong actor. Modern democracies cannot wage war without political and public support for long (Mack, 1975).

This strong actor / weak actor interaction on a global scale catapults many regions of the world into perpetual and indeterminate states of war with no regard to the international rule of law, no clear distinction between peace and war, and between combatant and non-combatant. This clear blurring of traditional boundaries means that this special type of war can turn into a factor producing and reproducing itself, hence deteriorating all aspects of human life. It permeates life with violence and offers little possibility to differentiate between inside and outside, and between home and abroad (Hardt \& Negri, 2004). In this special type of war nothing is just or unjust, right or wrong. Justice, injustice and law have no place in it as there is no common power and no law since force and fraud are the cardinal virtues (Hobbes, 1996).

Strong actor / weak actor interaction on a global scale means that traditional 
limitations blur both in space and time. This special type of war can continue for an indefinite period or it can have no end at all. Due to the uninterrupted, continuous cycle of terror and counter-terror the strong actor must win again and again, every day. Strong actor / weak actor interaction is the product of a rebellion against a legitimate world order not convenient for many, the exercise of brutal and often indiscriminate violence against humans and nearly all aspects of human rights (Hardt \& Negri, 2004).

\section{Problem with Causal Explanations}

Over years, many scholars wanted to come up with a scientific explanation why, despite all odds, the weak actor can prevail. The reason for scientific explanations is simple: science has a well-defined method, uses a set of coordinated knowledge and, at least in theory, delivers facts that stand for certain values. The science of war, which is in some countries called military science together with the resulting explanations, cannot be exact since it has to address the human element. This element refers to the humans themselves and their intricate interactions. Humans are able to adapt to the challenges posed by altering conditions and circumstances, which are in a perpetual flux. A scientific method to examine strong actor / weak actor interaction requires experience, reasoning and imagination, but also sensation, observation, reflection, and decision. The clear causal chain in which sensation / observation lead to reflection / reasoning and to decision is at the core of science. The logic behind is made up of rational thought. This can either be analogical, inductive or deductive. It is analogical if it moves from particular to particular, inductive if it points from particular to universal or general, and deductive if it points the other way round as the inference moves from universal or general to particular. For strong actor / weak actor interaction, all methods apply.
Due to the multitude of factors and the involvement of the human element most causes cannot be linked together with effects on a rational basis and remain unknown (Fuller, 1923; Fuller, 1937). This special type of war is composed of a complex web of interconnected constituents. The result is circular causation often in the form of vicious circles in which causes and effects connect through feedback loops. Thus things can escalate since tiny differences between causes often lead to entirely different and unexpected effects. These attributes work against most generalization attempts and stand for the impossibility to predict any future time path in the form of causal chains (Stacey, 1996). This special type of war stands for disguised correlations but not for detectable causal chains. It seems so that humans tend to disregard the difference between correlation of certain attributes and causal relationships (Christensen \& Raynor, 2003).

The Prussian theorist, Carl von Clausewitz shaped Western military thinking more than any other. His early death did not allow him to finish his epic volume properly, but even in its incomplete form, On War has a premier place among the most influential and insightful books ever written on the topic. Clausewitz was aware of the human dimension of war and the involvement of the human element. $\mathrm{He}$ also knew about circular causality for which he devoted a detailed analysis on the way causal relationships evolve in war. Book two, chapter five bears the title Critical Analysis. In this particular chapter Clausewitz attempted to address causality in war and analyse causal relationships and the way they unfold. He asserted that facts and the underlying motives are never fully known in wars; therefore the linking of effects with causes is very difficult. Most causes remain unknown in war for a multiple of reasons such as intentional concealment or improper recording. Effects do not necessarily come from known causes 
since one finds always gaps in the causeand-effect relationships the ignorance of which can cause serious challenges and problems. Clausewitz was sure that effects in war are not traceable back to a single cause as there are several concurrent causes simultaneously at work. Tracing the effects back to their causes is not sufficient unless the causes themselves cannot be assessed correctly. This requires a thorough investigation of the nature of effects otherwise one faces the danger of unending arguments with no conclusion. In terms of effects and the causes it is impossible to establish any meaningful law or standard, albeit in the process of judgement a certain reliance on aids might be helpful (Clausewitz, 1993).

Any investigation aimed at detecting a causal relationship becomes easy only if cause and effect are close in time and space. Due to the human element everything in war is interconnected. A single effect can have a significant influence on subsequent events since every available means influences the ultimate result. Causality in war, especially circular causality, means that effects can also become causes. An effect at any one level can become questionable at a higher level and demands a new way of judgement. The problem with this chain of hierarchical relationships is that the distance between a cause and an effect is proportional with the number of additional factors involved. Consequently, not only the range of factors but also that of forces involved grows: the higher the effect sought the greater must be the cause by which it can be achieved. To better comprehend the intricate and difficult nature of cause-andeffect relationships in war, Clausewitz advocated a thorough analysis with which it becomes possible to highlight various and essential connections. This analytic approach is very important since people are biased and often blindly follow single or simple lines of thought. In terms of higher order forces and effects in the psychological domain reliable evaluation becomes more and more difficult. Regarding the will, which for Clausewitz reflected the interplay of courage and fear, even a thorough analysis cannot contribute to the achievement of desirable outcomes (Clausewitz, 1993).

In the subsequent book Clausewitz emphasised that any strategic theory of war must consider material factors and moral qualities since physical and psychological effects are not necessarily distinct from each other, but form an organic whole. In the book on War Plans he insisted that there are so many factors influencing military campaigns that the near infinite distance between causes and effects stands for endless combinations. The only thing achievable is to approach war in a comprehensive way and avoid narrowminded formulas in the process of problem solving. The capacity of mind together with the actions taken to respond to immediate challenges is much more important in war than any product of thought (Clausewitz, 1993). Scientific method gives a sufficient tool to extract knowledge from the unknown by using certain laws or principles that have a universal inference. None of the laws or the principles is of greater value or more important than the other, but one should consider them in harmony and know their value (Fuller, 1923).

Causality stands for a search to establish a series of logical statements revealing a linear connection in which a particular effect results from a particular cause. However, this special type of war and the human element involved do not provide anyone with a line logical of deductions. Instead, one finds a gap between the principles applied and actual events observed which cannot always be bridged by cause-and-effect chains (Clausewitz, 1993). 


\section{Multitude of Factors}

Despite the limitations as detailed above it makes sense to approach strong actor / weak actor interaction and the resulting special type of war with a scientific method. The human element too is not necessary incompatible with determinism, except when it has no determining conditions for its occurrence (Lorenz, 1993). Strong actor / weak actor interaction is full of diffuse, intermittent, dispersed, and irregular processes that feature fluid and dysphasic movements and constantly erode most attempts to achieve symmetry and order. The special type of war stands for a certain interplay that balances between expanding heterogeneity and the striving for homogeneity (Saperstein, 1995). Strong actor / weak actor interaction stands for dynamic equilibrium featuring inconsistency and incompleteness. Even much simpler settings that attempted to model its war's dynamics show signs of non-linearity and display instability. The first combat model of warfare was the Lanchester equations, introduced in 1914. They were a pair of coupled differentials to estimate casualty rates mathematically in the form of loss ratios in combat. At the beginning of the $21^{\text {st }}$ century the equations are sketchy and appear to be very crude and clumsy. Increasing computing power, rapid advances in information technology in the last decades of the $20^{\text {th }}$ century enabled analysts to better cognize war's complex features, including the human element. The relatively simple equations of the Lanchester differentials got replaced by more complex models, which also yielded divergent and unexpected results, hence signs of instability (Speight, 2002).

The analysts introduced terms such as structural variance and non-monotonicity to describe the occasional and erratic behaviour that came from the strictly deterministic mechanism of the models employed. Irregular functions of certain input parameters resulted in outputs that were seen as the programmers' mistakes. First efforts aimed at finding techniques to reduce these model anomalies, but later research discovered that infinitely small factors, for example rounding errors, can cause model instability. Dynamic instability is an inherent feature of complex modelling, which clearly points toward a broader generalization. If deterministic, but complex combat models and controlled conditions display irregular outputs, than wars especially those belong to this special type that feature a low level of determinism are bound to do so. Real war is much more complex than any combat model. If simple or simplistic computer models show structural variance and non-monotonicity then the instability of the modelled reality is very much implied (Speight, 2003).

Strong actor / weak actor interaction does not necessarily allow, even when advantageous conditions exist, for the identification of clear cause-and-effect relationships. The arising special type of war indicates that strong actor / weak actor interaction contains more than just acts of reason, and reasoning is not its dominant activity. The causes are not absolute or the only ones possible. Many remains hidden in the dark and guessed only resulting in numerous possibilities, wrong turns and dead-ends. Desired effects are occasionally produced by the fortunate amplification of the limited means applied. This special type of war is real war and has its natural inertia. The proverbial friction of war reflects the human element featuring human failures that include inconsistency, imprecision and timidity. Friction indicates conditions and circumstances that do not contain much logic in reasoning. Due to the structural variance and non-monotonicity caused by a multitude of factors it is difficult to fully comprehend the resistance the strong actor faces, and there will always be impossible to precisely align the ends sought with the means applied. Causal relationships, methods 
borrowed from exact sciences and logic based on mathematics are of little help since waging this sort of special war remains an artistic activity in the fullest and widest meaning of the term. The vast variety of factors together with the bewildering array of circumstances posed by the environment result that methodological examinations are often impossible. The conclusions reached are as much causal as reflecting intuitive comparisons and the qualities of the mind. The act of waging war very much reflects the human element. The actors involved often take and execute on the spot decisions and not necessarily apply general and universally relevant rules (Clausewitz, 1993).

Addressing this special type of war in an exclusive way by focusing on cause-andeffect relationships inadequately captures its underlying dynamics. Jomini, another classic of Western military thinking had the intention to establish a scientific theory of war and tried to put together a meaningful set of standardised methods or phenomena. In his attempt to do so Jomini developed four maxims for the fundamental principle of war, eight rules for selecting tactical positions, twelve orders of battle, thirteen points for fighting battles, five directions for an attack by main force, three rules for pursuit, eighteen points for the movements of armies, and nineteen rules for the use of artillery (Jomini, 1992). Jomini should serve as good example for the fact that searching for analytic principles that enables a scientific inquiry does not address the dynamics of real war fought with blood and guts. Rigid, dogmatic and prescriptive thinking has little or no relevance and even if applied, the result is a strong limitation in comprehension (Shy, 1986).

\section{Adaptation and Consequences}

To better understand strong actor / weak actor interaction one must reject classical theorizing and promote complexity thinking that requires a shift from worshipping mechanics to better appreciating biology (Modelski \& Poznansky, 1996). In this special type of war there is no way to filter out the many changes that occur during its course and treat them in perfect isolation. There are an infinite number of ramifications on various levels and of various scales as the strong actor / weak actor interaction tweaks and alters constantly. The ramifications themselves initiate a complicated flow of effects, each of which entails various sorts of compensatory adjustments to handle the haphazard mess produced. Strong actor / weak actor interaction very often equals a loose patchwork of provisional reactions stitched together from what was there already. The consequences, whatever they are, must often be accepted by looking back as they cannot necessarily be planned by looking ahead (Pittendrigh, 1958).

This shift to biology can also better accommodate the human ability to adapt to the various conditions posed by the changing circumstances of the strong actor / weak actor interaction. The necessary move from statics to dynamics, from time-free to time-prone reality, from determinism to probability and chance, and from uniformity to variation and diversity are at the heart of this approach. Complexity thinking has very much to do with adaptation, which in its purest form often equals tinkering. Adaptation features various corrections to secondary problems caused during the process. It is at the heart of natural selection and sweeps up countless minuscule details that come to the fore after the occurrence of a big original error. Adaptation helps the species to correct major design flaws to find a good enough compensation for the initial error. Major mutations stand for biological innovations that very often evolve from organs of completely different kind and not from old organs doing the same job. Even successful major mutations that cause an improvement often require some sort of follow-on tinkering that includes countless mutations 
on smaller scale to iron out the kinks just created. Initial mistakes caused by major mutations are improved in a post-hoc fashion by making ad hoc compensatory modifications that include various sorts of budges, fixes, and kludges (Dawkins, 2009).

Adaptation requires creativity, constant change, taking advantage of evolving situations and accepting limitations in terms of comprehension, prediction and control. In the strong actor / weak actor interaction much depends on chance as the emerging possibilities and prevailing circumstances always form a broad spectrum. Complexity thinking requires flexibility and the appreciation of novelty, robustness and exploiting dynamic equilibrium, and the ability to take advantage of emerging windows of opportunities. Although it is very often unpalatable for the strong actor, he must embrace open strategic options and exploit probabilistic occurrences to make the best within his domain of his focus. It is sometimes better for the strong actor to let various sorts of pattern emerge than to commit resources too early to maintaining an artificial and false consistency. The traditional focused vision must yield to a peripheral vision to detect and take advantage of the various opportunities that unfold and to tinker consistently in the process of adaptation to get a grip on unpredictable nature of this special type of war. Peripheral vision and tinkering, not a causal focus enable the strong actor to handle the unfolding dynamics of events (Pascale, 1999).

The shift to biology and adaptation indicates that this special type of war requires only general statements in advance to kick-off activities rather than to adhere to a detailed plan. Certainly, guidelines must be laid down to put the forces of the strong actor into gear but as the interaction with the weak actor gains momentum, details that guide the subsequent actions become known anyway. A good example for adaptation and tinkering was the 1967
Arab-Israeli war in which for the Israelis only the first day was planned in detail, the rest was pure improvisation (Creveld, 1985).

\section{Conclusion}

In a globalized world strong actor / weak actor interaction poses a serious challenge. Globalization provides the latter actor with an abundance of opportunities. From a military point of view strong actor / weak actor interaction arises when one actor prosecutes a special type of war featuring asymmetry, irregularity and low intensity waged by a loose network of combatants. Fighting such networks scarcely displaying hierarchical structures is inherently difficult, in some cases impossible for the strong actor. As a result the enmity between the actors can become real over time and include continuous terror and counter-terror featuring cruelty, collective punishment, even genocide. The unavoidable circle of terror and counter-terror including various sorts of war crime requires premeditated actions to address the insecurity, anxiety, and common mistrust inherent in the strong actor / weak actor interaction. This special type of war requires to a great extent that the strong actor conducts, among others, psychological operations, information operations, and focuses on civil-military relations.

Strong actor / weak actor interaction and the resulting special type of war blurs limitations inherent in traditional war in time and space. It catapults many regions of the world into perpetual and indeterminate states of war with no regard to the international rule of law, no clear distinction between peace and war, and between combatant and non-combatant. The resulting special type of war is full of dispersed, diffuse, intermittent and irregular processes that feature fluid and dysphasic movements constantly eroding attempts to achieve symmetry and order. In such an environment, doctrinal models that prescribe the principles and guidelines of warfare 
may be constantly subject to review as to their purpose and effectiveness in achieving an end state, that is, conflict resolution introduces additional uncertainty. The strong actor faces the constant challenge marked by fractalization and drive for homogeneity. Terror and counter-terror becomes a vicious circle that display catastrophes, accidents, missed opportunities, numerous possibilities, probabilities and wrong turns.

To better understand the complexity inherent in strong actor / weak actor interaction one must reject classical theorizing and promote a way of thinking that requires a shift from mechanics to biology. The emphasis must move from statics to dynamics, from time-free to timeprone reality, from determinism to probability and chance, and from uniformity to variation and diversity. This way on can better address creativity, constant change, evolving situations and limitations regarding comprehension, prediction and control inherent in this special type of war. In the strong actor / weak actor interaction much depends on chance as possibilities always emerge and form a broad spectrum. The shift to biology means that the emphasis will be on flexibility, robustness, and the ability to exploit constantly moving windows of opportunity thus addressing the challenge posed by the complex web of interconnected constituents.

This shift is even more needed as the security posture, values and interests of NATO's member states cannot be maintained without the occasional involvement into strong actor / weak actor interaction and the resulting special type of war. It is more than a warning that the two major involvements of NATO in Iraq and Afghanistan were, despite the clear technological and material advantage, long campaigns that did not end with a clear defeat of the weak actor.

\section{REFERENCES}

Arreguin-Toft, I. (2001). How the Weak Win Wars: A Theory of Asymmetric Conflict. International Security, Vol. 26, Issue 1, 93-128.

Callwell, Ch.E. (1906) Small Wars, their Principles and Practice. London: General Staff - War Office.

Christensen, C.M., \& Raynor, M.E. (2003). Why Hard-Nosed Executives Should Care about Management Theory. Harvard Business Review, Vol. 81, Issue 9, 66-74.

Clausewitz, C. (1993). On War. London: Everyman's Library.

Coker, Ch. (2002). Waging War without Warriors, the Changing Culture of Military Conflict. IISS Studies in International Security. Boulder: Lynne Rienner Publishers.

Creveld, M. (1985). Command in War. Cambridge: Harvard University Press.

Creveld, M. (1991). The Transformation of War. New York: The Free Press.

Dawkins, R. (2009). The Greatest Show on Earth. The Evidence for Evolution. New York: The Free Press.

Fuller, J.F.C. (1923). The Reformation of War. London: Hutchinson and Co.

Fuller, J.F.C. (1937). The Foundations of the Science of War. London: Hutchinson and Co.

Hardt, M., \& Negri, A. (2004). Multitude: War and Democracy in the Age of Empire. London: Penguin Press.

Heintschel von Heinegg, W. (2012). Asymmetric Warfare: How to Respond? International Law Studies, Vol. 87, 463-480.

Hobbes, T. (1996). Leviathan. Oxford: Oxford University Press.

Jomini, B.A.H. (1992). The Art of War. London: Stackpole Books. 

211-234

Kissinger, H.A. (1969). The Vietnam Negotiations. Foreign Affairs, Vol. 48, Issue 2,

Lorenz, E.N. (1993). The Essence of Chaos. London: UCL Press.

Mack, A. (1975). Why Big Nations Looses Small Wars: The Politics of Asymmetric Conflicts. World Politics, Vol. 27, Issue 2, 175-200.

Modelski, G. \& Poznanski, K. (1996). Evolutionary Paradigms in the Social Sciences. International Studies Quarterly, Vol. 40, Issue 3, 315-319

Pascale, R.T. (1999). Surfing the Edge of Chaos. MIT Sloan Management Review, Vol. 40, Issue 3, 83-94.

Pittendrigh, C.S. (1958). Adaptation, natural selection, and behavior. In: Roe, A. \& Simpson, G. G. (Eds.) (pp. 390-419). Behavior and Evolution. New Haven: Yale University Press.

Porkolab, I. (2013). When the Goldfish meets the Anaconda: A modern fable on unconventional leadership. Counter Terrorism Exchange, Vol. 3, Issue 3, 5-21.

Saperstein, A.M. (1995). War and Chaos. American Scientist, Vol. 83, Issue 6, 548-557.

Schmitt, C. (1963): The Theory of the Partisan, a Commentary / Remark on the Concept of the Political. Berlin: Duncker \& Humblot.

Shy, J. (2010). Jomini. In: Paret, P., Craig, G.A. \& Gilbert, F.: Makers of Modern Strategy from Machiavelli to the Nuclear Age. Princeton: Princeton University Press, 143-185.

Speight, L.R. (2002). Lanchester's Equation and the Structure of the Operational Campaign: Between-Campaign Effects. Military Operations Research, Vol. 7, Issue 2, 15-33.

Speight, L.R. (2003). 'Structural Variance' or 'Non-Monotonicity' Effects in Combat Models: A Review. Military Operations Research, Vol. 8, Issue 1, 17-33.

Stacey, R.D. (1996). Strategic Management \& Organisational Dynamics. Toronto: Pitman Publishing.

Zinni, A.C. (2000). A Commander Reflects, What will be the operations of the future? Proceedings, Vol. 126, Issue 169, 34-36. 